\title{
Integrated cardiothoracic surgery: Developing a successful residency application
}

\author{
Benjamin Smood, MD, ${ }^{\mathrm{a}}$ Stephanie N. Nguyen, MD, ${ }^{\mathrm{b}}$ John J. Kelly, MD, ${ }^{\mathrm{a}}$ and Jason J. Han, MD
}

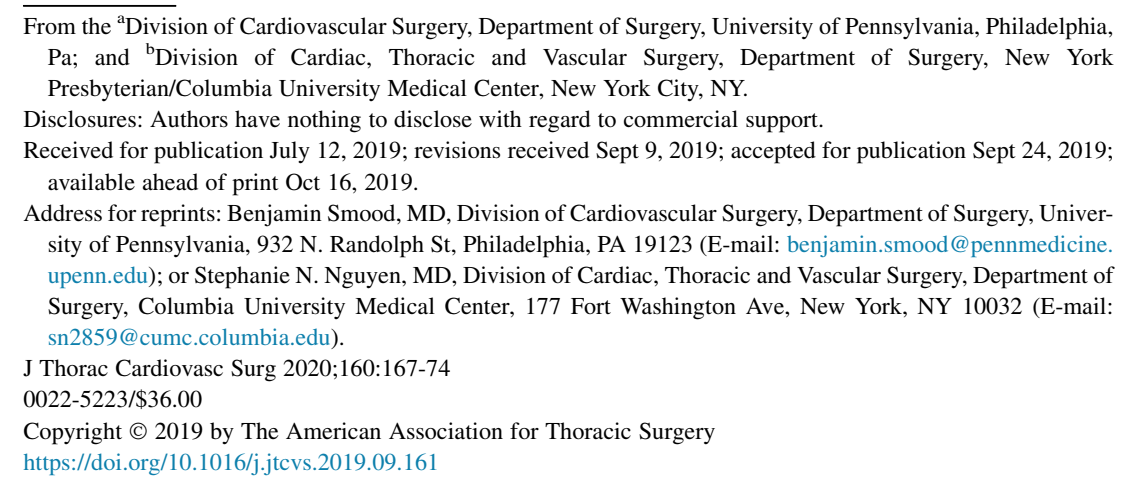

The establishment of integrated cardiothoracic (CT) surgery programs is shaping the future of the specialty's surgical education. ${ }^{1}$ Since their introduction in 2007, integrated programs (IPs) have been competitive residencies that attract some of the most driven and high-achieving medical students in the United States. ${ }^{2}$ Currently, only 36 positions at 28 programs are offered through the National Resident Matching Program, which constitute just $0.1 \%$ of all allopathic positions. ${ }^{3}$ In 2019, there were 209 applicants, with an average of 140 applications received per program. ${ }^{4}$ To be considered for one of these positions, it is imperative for candidates to be informed early regarding how to develop a strong and well-rounded application that demonstrates their commitment to the long and challenging training of CT surgery. ${ }^{5,6}$ The characteristics of those who successfully match into IPs have been described, ${ }^{7,8}$ but the process of developing a competitive application is daunting and unclear.

Individuals interested in applying to IPs derive great benefit from peers who are familiar with the process. Unfortunately, not all applicants are afforded this guidance and peer-mentorship. Past IP applicants have a responsibility to pay it forward and mentor others seeking a similar training path, which here we attempt to do. We aim to assist medical students with an interest in CT surgery and those who are considering IPs in developing a successful residency application, as we ourselves are past applicants and have entered training in each of the last 3 application cycles. In composing this commentary, we have sought input from past and prospective applicants regarding what information is valuable and desired. With this perspective, we hope applicants will be better equipped to achieve what is necessary throughout their medical education to successfully pursue an integrated CT surgery residency. We supplement data from previous studies and surveys with our personal

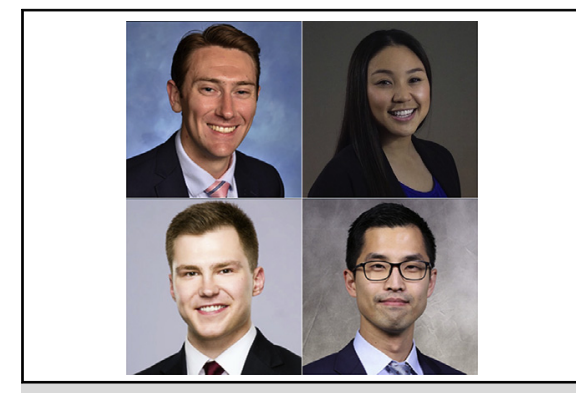

Top: Benjamin Smood (postgraduate year [PGY]-1); Stephanie Nguyen (PGY-1); Bottom: John Kelly (PGY-2); Jason Han (PGY-3)

\section{Central Message}

Exemplary academic and extracurricular performances are undeniable prerequisites for integrated program applicants. Perhaps more important is demonstrating a commitment to cardiothoracic surgery.

\section{Perspective}

Individuals interested in applying to integrated cardiothoracic surgery residencies derive great benefit from peers who are familiar with the process. Unfortunately, not everyone is afforded this guidance and peer-mentorship before applying. Past integrated program applicants have a responsibility to pay it forward and mentor others seeking a similar training path which here we attempt to do.

See Commentary on page 175 .

experience in an effort to provide detailed guidance for trainees interested in IPs.

\section{DECIDING EARLY TO APPLY TO INTEGRATED CT SURGERY PROGRAMS}

One half of IP applicants decide to pursue a career in CT surgery before or during their first 2 years of medical school. ${ }^{9}$ Realizing one's commitment to CT surgery so early necessitates adequate exposure throughout the first years of medical school. ${ }^{7}$ Shadowing, research, and discussions with CT mentors is important to understanding the demands and rewards of this specialty throughout training and beyond. It cannot be overemphasized that students applying to IPs must be absolutely certain that they want to pursue a career in CT surgery. Unlike other training pathways, IP graduates are not board- 
certified in general surgery. Avoiding resident attrition is of paramount importance to program directors. ${ }^{5}$ Individuals that are even remotely considering other surgical subspecialties are strongly encouraged against applying to IPs.

Surprisingly, only a small proportion of unmatched IP applicants end up pursuing a career in CT surgery, ${ }^{10}$ which may reflect the focused and abbreviated training pathway of IPs as a consideration in pursuing CT surgery as a career. ${ }^{7}$ However, it must be noted that viewing IPs as a shortcut to becoming a CT surgeon is misguided. Most applicants envision a career in academic surgery, ${ }^{9}$ and some IPs encourage/ require academic pursuits of 2 years, extending training to an 8-year commitment. ${ }^{11}$ Candidates should consider this when evaluating programs. ${ }^{11}$ Moreover, many graduates will pursue additional fellowships to develop their niche as academic surgeons. Therefore, if one chooses to become a CT surgeon, training for a minimum of 6 years, and in some cases close to a decade, should be palatable, regardless of the training route.

Because there are so few IPs, the odds of obtaining one of the IP positions is objectively low., ${ }^{3,4,7,8}$ Applicants committed to a career in CT surgery must thoroughly apply to general surgery, including those with " $4+3$ Fast-Track" CT surgery programs. The traditional CT training path entails completing 5 years of general surgery and then applying for a 2- or 3-year CT fellowship. A " $4+3$ FastTrack" program accelerates the transition from general surgery to CT fellowship. The first 4 years are spent in general surgery training, with the final 3 years dedicated to CT fellowship. At least one institution has individuals apply directly to the $4+3$ program out of medical school. More frequently, $4+3$ programs select 1 or 2 of their general surgery residents (often after the second year of residency). Although acceptance into the $4+3$ program may save a year of training compared to the traditional path, acceptance into these programs is not guaranteed, in which case residents completing their general surgery training would be required to apply for a traditional fellowship.

Perhaps the greatest advantage of IPs is the early and increased exposure to multiple facets of CT surgery. ${ }^{8}$ Junior-resident rotations include thoracic and cardiac surgery, cardiac anesthesia, and cardiac critical care. ${ }^{12}$ Although the heterogeneity of curriculum among IPs may be considered a disadvantage, ${ }^{8}$ and the proportion of time on varying services differs across institutions, ${ }^{11}$ this early exposure provides an essential experience in patient management and operative technique translatable to CT surgery. ${ }^{1}$ The vast majority of those who match into IPs are satisfied with their career choice and training programs. ${ }^{8}$ Having a strong early foundation in $\mathrm{CT}$ principles enables residents to focus efforts toward an immersive CT operative experience during their senior fellowship years.

In this light, much of the IP application and interview process seeks to identify high-achieving applicants who remain committed to pursuing a career in CT surgery despite understanding the challenges that lie ahead. ${ }^{5,6} \mathrm{We}$ offer guidance in developing a competitive application for those who consider applying to IPs.

\section{DEVELOPING A COMPETITIVE APPLICATION Preclinical Years}

Medical students ought to strive for academic excellence to distinguish themselves in the competitive pool of IP applicants. Objective, tangible metrics are frequently used by programs to develop an initial list of potential candidates, ${ }^{5}$ and consistency of grades is among the most valued factors in selecting applicants to interview ${ }^{6}$ (Table 1). Many schools are transitioning to pass/fail grading systems in the preclinical years. Applicants should strive to earn recognition of their consistent top performance with respect to their peers if such distinctions are available. Merits demonstrating a wholistic picture of academic accomplishment, such as Alpha Omega Alpha membership, may be more important than class rank (Table 1). In any case, excelling on standardized national examinations is critical, as these afford objective comparisons of academic performance amongst peers nationwide. On average, recent first-year IP residents have Step 1 and Step 2 scores of $244 \pm 10.9$ (mean \pm standard deviation), and $249 \pm 13.2$, respectively $^{13}$ (Figure 1). Some IPs report target scores when considering which applicants to interview and may not grant interviews when Step 1 scores fall below $230 .{ }^{13}$ Although no complete data exist for these cutoffs, in considering these metrics, we recommend setting a personal goal of scoring 250 on both Step 1 and Step 2. We recommend taking Step 2 (both the Clinical Knowledge and Clinical Skills exams) before submitting applications so that studying does not become a distraction throughout interview season, although these may not be required for IPs before offering interviews (Table 1).

\section{Clinical Rotations}

Similar to the preclinical years, excelling in clinical clerkships, especially the core surgical and internal medicine rotations, is of utmost importance (Table 1) ${ }^{5,6}$ Clinical correlates on every clerkship provide learning opportunities applicable to CT surgery, and high marks in these rotations demonstrate interpersonal skills, teamwork, leadership, and professionalism. ${ }^{5}$ These form the basis of the Medical Student Performance Evaluation (ie, MSPE/Dean's Letter), a comprehensive assessment of student's performance that is valuable to IPs in selecting applicants to interview (Table 1).

With this approach to clinical rotations, even the minority of students deciding late into their third year to apply to IPs ${ }^{9}$ will be well-positioned for a competitive application. Nevertheless, it is recommended that by the end of third 
TABLE 1. Percentage of programs citing each factor and mean importance rating for each factor in selecting applicants to interview and in ranking applicants: select results from the National Resident Matching Program 2018 Director's Survey (N=9 programs)

\begin{tabular}{|c|c|c|c|c|}
\hline \multirow[b]{2}{*}{ Factor } & \multicolumn{2}{|c|}{$\begin{array}{l}\text { Considered in selecting } \\
\text { applicants to interview }\end{array}$} & \multicolumn{2}{|c|}{$\begin{array}{l}\text { Considered in ranking } \\
\text { applicants }(\mathbf{N}=9)\end{array}$} \\
\hline & $\%$ Citing factor & Average rating & $\%$ Citing factor & Average rating \\
\hline Consistency of grades & 67 & 4.8 & 56 & 4.4 \\
\hline Graduate of highly regarded US medical school & 78 & 4.7 & 44 & 4.3 \\
\hline USMLE Step 2 CK/COMLEX Level 2 CE score & 56 & 4.5 & 44 & 4.8 \\
\hline Grades in clerkship in desired specialty & 78 & 4.5 & 56 & 4.2 \\
\hline Evidence of professionalism and ethics & 78 & 4.5 & 56 & 4.3 \\
\hline Passing USMLE Step 2 CS/COMLEX Level 2 PE & 56 & 4.5 & 22 & 5 \\
\hline Awards or special honors in basic sciences & 33 & 4.5 & 33 & 4 \\
\hline Letters of recommendation in the specialty & 100 & 4.4 & 89 & 4.3 \\
\hline Grades in required clerkships & 78 & 4.3 & 67 & 4.3 \\
\hline Perceived commitment to specialty & 100 & 4.3 & 89 & 4.4 \\
\hline Perceived interest in program & 44 & 4.3 & 44 & 4.5 \\
\hline Awards or special honors in clerkship in desired specialty & 78 & 4.3 & 56 & 3.8 \\
\hline Interest in academic career & 56 & 4.3 & 67 & 4.2 \\
\hline Personal previous knowledge of the applicant & 78 & 4.2 & 44 & 4.8 \\
\hline Leadership qualities & 89 & 4.2 & 78 & 4.6 \\
\hline Demonstrated involvement and interest in research & 67 & 4.2 & 67 & 4.2 \\
\hline USMLE Step 1/COMLEX Level 1 score & 89 & 4.1 & 56 & 4.8 \\
\hline Medical Student Performance Evaluation (MSPE/Dean's Letter) & 89 & 4.1 & 78 & 4.6 \\
\hline Alpha Omega Alpha (AOA) membership & 89 & 4.1 & 56 & 4.6 \\
\hline Volunteer/extracurricular experiences & 56 & 4 & 44 & 4.3 \\
\hline Awards or special honors in clinical clerkships & 67 & 4 & 67 & 4.2 \\
\hline Personal statement & 100 & 3.9 & 67 & 3.8 \\
\hline Class ranking/quartile & 67 & 3.8 & 67 & 4.2 \\
\hline Audition elective/rotation within your department & 67 & 3.8 & 78 & 4.4 \\
\hline Lack of gaps in medical education & 67 & 3.8 & 44 & 4 \\
\hline Other life experience & 78 & 3.7 & 33 & 3.7 \\
\hline Away rotation in your specialty at another institution & 67 & 3.7 & 56 & 3.8 \\
\hline Gold Humanism Honor Society (GHHS) membership & 56 & 3.3 & 44 & 4 \\
\hline
\end{tabular}

Ratings on a scale from 1 (not at all important) to 5 (very important). ${ }^{6} U S M L E$, United States Medical Licensing Examination; $C K$, Clinical Knowledge; $C E$, Cognitive Evaluation; CS, Clinical Skills; $P E$, Performance Evaluation.

year, applicants should be fully committed to CT surgery if they choose to apply to IPs.

\section{Work and Volunteer Experiences}

The standardized form for the Electronic Residency Application Service contains 3 categories for extracurricular activities when applying to residency-work, volunteering, and research. The preclinical years of medical school provide an optimal opportunity for establishing longitudinal commitments in each of these. Because a perceived commitment to CT surgery is among the most frequently cited factors in offering interviews (Table 1$){ }^{5}$
IP applicants should have extracurriculars that are at least tangentially related to the specialty. On average, entering IP residents have 3 and 6 work and volunteer experiences, respectively. ${ }^{13}$ Find a committed interest. Some applicants will spend time in student-run medical clinics, as interpreters or abroad, tutoring high school or medical students, serving on admissions committees, or as an officer in their student body. Others might lead suturing workshops or create CT journal clubs and interest groups for junior students. These endeavors should demonstrate well-rounded leadership that extends beyond requisite academic excellence. Being able to speak in depth about these experiences 


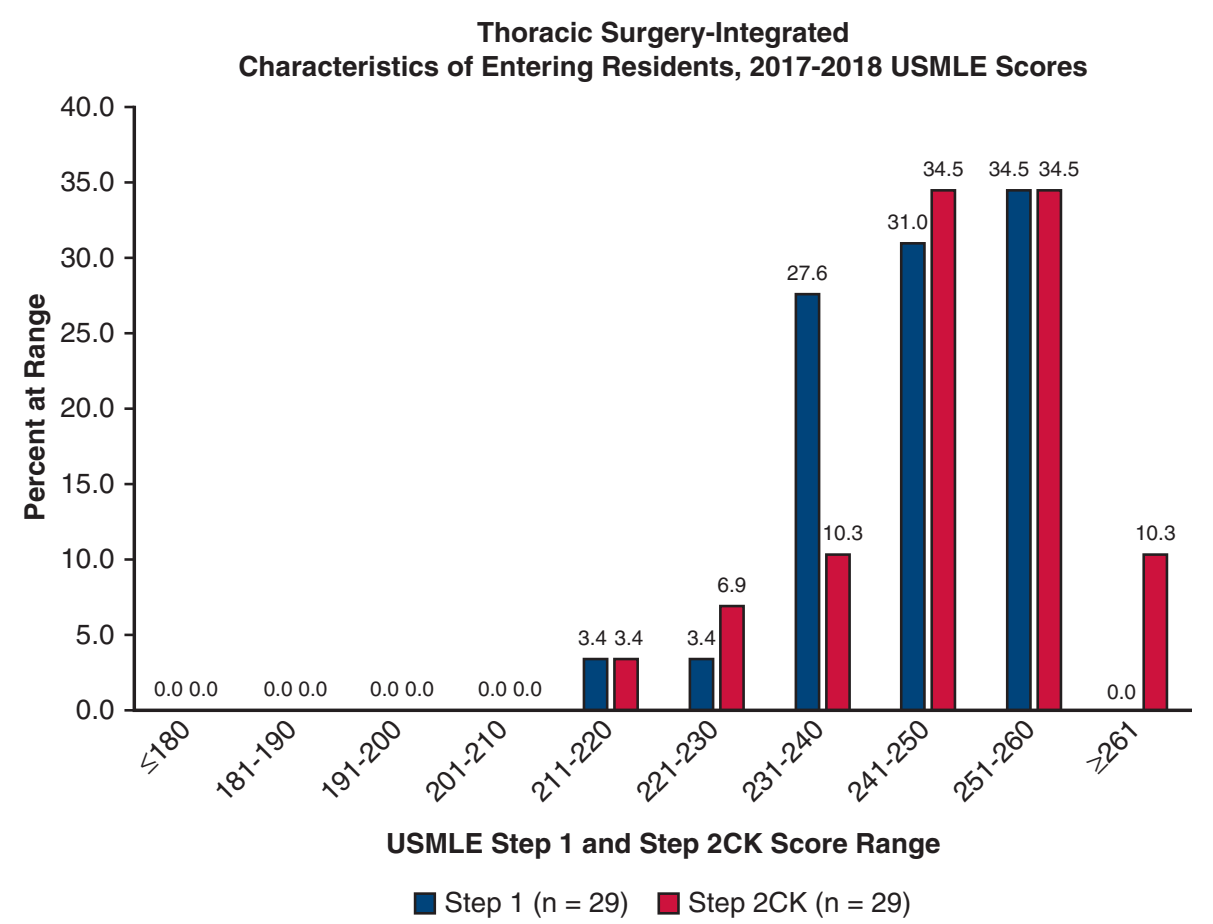

FIGURE 1. Average USMLE Step 1 and Step 2 CK scores of US MD graduates entering integrated thoracic surgery residency programs. The mean Step 1 and Step 2 scores for first-year integrated cardiothoracic residents are $244 \pm 10.9$ (mean \pm standard deviation) and $249 \pm 13.2$, respectively. The authors recommend that applicants to integrated programs set a personal goal of scoring 250 on both examinations to remain competitive in securing interviews. Figure data are lower $(\mathrm{N}=29)$ than residency positions filled in $2017(\mathrm{~N}=34)$ because some data for foreign-trained physicians and others are missing. ${ }^{3,13}$ (C2019 Association of American Medical Colleges. May be reproduced and distributed with attribution for educational or noncommercial purposes only. ${ }^{13}$ USMLE, United States Medical Licensing Examination; US MD, United States Medical Doctor; $C K$, clinical knowledge.

and their influence in pursuing a career in CT surgery, we believe, is much more valuable than a myriad of superficial activities that merely serve to bulk one's curriculum vitae. ${ }^{5}$

Although it is generally not advised to fill applications with accomplishments before medical school, unique life experiences demonstrating maturity are valuable. Similarly, elite performers, such as collegiate athletes or accomplished musicians, should advertise this. The cognitive psychology required to reach such mastery is translatable to the sacrifice and discipline required of CT surgeons. ${ }^{14}$ These activities can also provide a healthy avenue for preserving one's well-being during the rigors of CT surgical training-an intangible trait that is difficult to evaluate, but one that is valued. ${ }^{5}$

\section{Research Experience}

Students are told ad nauseum that they must conduct research if they want to match into competitive surgical residencies. We identify baseline objective metrics for applicants interested in applying to IPs. On average, incoming IP residents have 4 research experiences (Figure 2), with 10.5 "publications" (original articles, abstracts, posters, and/or oral presentations) (Figure 3). Applicants should be ambitious in their research goals. Although some students elect to take a year off for dedicated research, this certainly is not necessary. In fact, it might be counterproductive if this time does not result in a prolific performance. Sufficient time exists in medical school to develop an outstanding investigative curriculum vitae.

At least one first-author paper is encouraged before submitting applications, as this demonstrates the important ability to lead a project to completion. To maximize productivity, we recommend students pursue 2 or 3 projects concomitantly. In balancing these, prospective applicants should be able to contribute as the second (or third) author on several additional publications. Supplementing original research with literature reviews, book chapters, and case reports is advised. For the most competitive IP applicants, we recommend that at least 5 original articles be submitted, in press, or preferably published by the time of application submission.

Thinking of projects in categories of basic science, clinical research, reviews/textbook chapters, and case reports can guide students in diversifying their publishing profile. Basic science and translational research might be considered the most impressive tier of publications, as achieving 


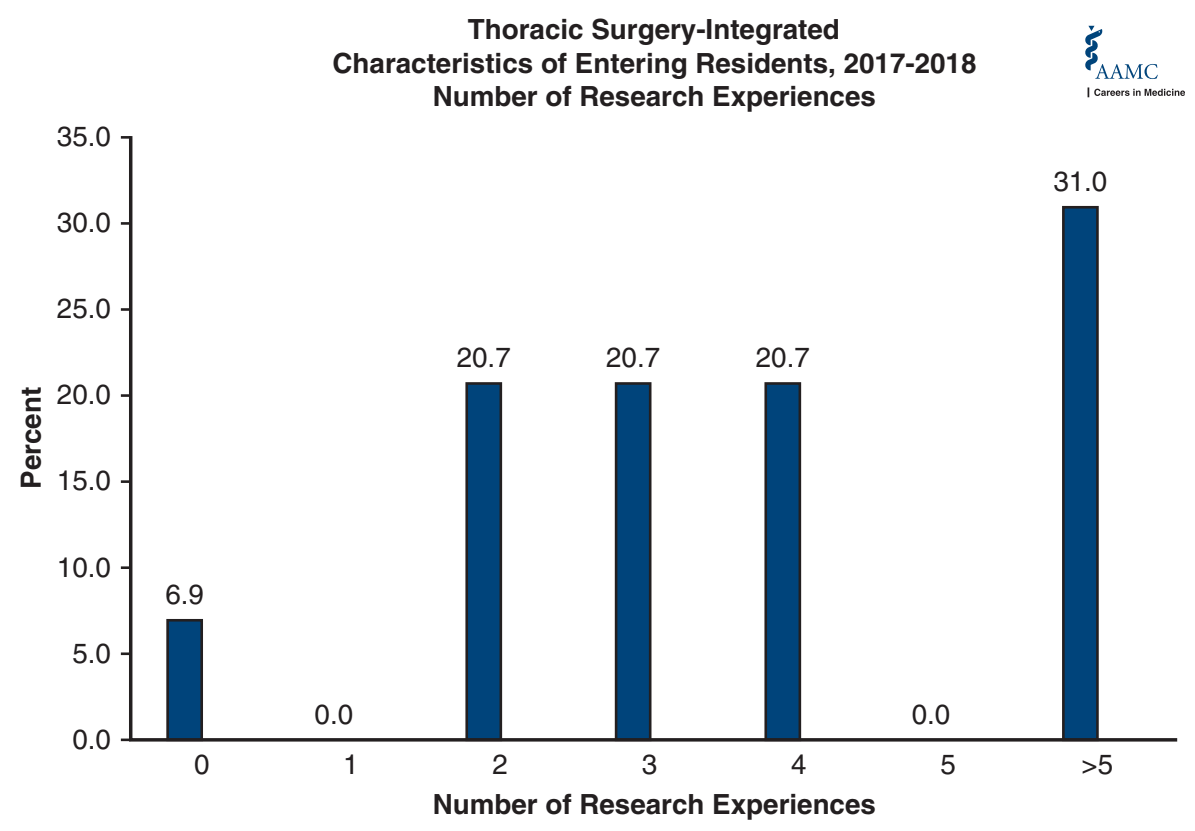

U.S. MD 2016-2017 Graduates ( $\mathrm{n}=29) \quad \square$ Other $(\mathrm{n}=0)$

FIGURE 2. Number of research experiences of medical graduates entering into integrated thoracic surgery residency programs. Incoming integrated residents, on average, have 4 research experiences. Figure data are lower $(\mathrm{N}=29)$ than residency positions filled in $2017(\mathrm{~N}=34)$ because some data for foreign-trained physicians and others are missing. ${ }^{3,13}$ (C2019 Association of American Medical Colleges. May be reproduced and distributed with attribution for educational or noncommercial purposes only. ${ }^{13}$ AAMC, Association of American Medical Colleges; US MD, United States Medical Doctor.

the evidence required for novel cellular, molecular, and/or biomechanical conclusions can take years to develop and bring to publication. Longitudinal experience in these endeavors, even when unpublished, can provide fruitful conversations during interviews.

In contrast to basic science, clinical outcomes research for students often consists of retrospective chart reviews. A vast amount of data exists in patient records that must be extracted and evaluated in light of a preformed question and hypothesis. Clinical research comes in many other forms, and one should strive to learn something new from each project, be it data-mining, statistical analysis, survey writing, or even the process of obtaining institutional review board approval. Although there are no guarantees, the chances of securing a publication is greater than with basic science and translational investigations.

For each project, applicants should attempt to present a poster and/or an oral presentation in pursuit of the ultimate goal-publication in a peer-reviewed journal. Do not hesitate to submit abstracts to school conferences or regional symposiums. Each chance to present is an opportunity to build a record of academic success. When applying to competitive scholarships and grants (described below), having a record of presentation even on smaller stages can add merit to one's application. Presenting research at national meetings provides a unique opportunity to interact with $\mathrm{CT}$ community members from across the country.

\section{FOSTERING EARLY RELATIONSHIPS IN CT SURGERY \\ Mentorship}

The benefits of identifying CT surgical mentors early in one's education are multifaceted. Students should introduce themselves to their home institution's faculty as soon as they develop an interest in CT surgery. Prospective applicants should inquire about weekly educational CT conferences, as attendance will reinforce their visibility within their home CT division and foster mentor/mentee relationships. Attempt to shadow at least once per month to reinvigorate one's commitment and dedication to the field, particularly during the isolating preclinical years.

Mentors offer research opportunities and can introduce applicants to faculty across the country at national meetings when presenting. Moreover, student's educational opportunities can be maximized in the operating room if trust has been developed over several years, allowing mentors to more thoroughly evaluate applicants in letters of recommendation (LOR). If an applicant's home program has a CT training program, resident-student mentorships can complement these opportunities.

\section{Networking}

Personal relationships are vitally important in the small community of CT surgery. Both LORs and a program's previous knowledge of an applicant are among the most 


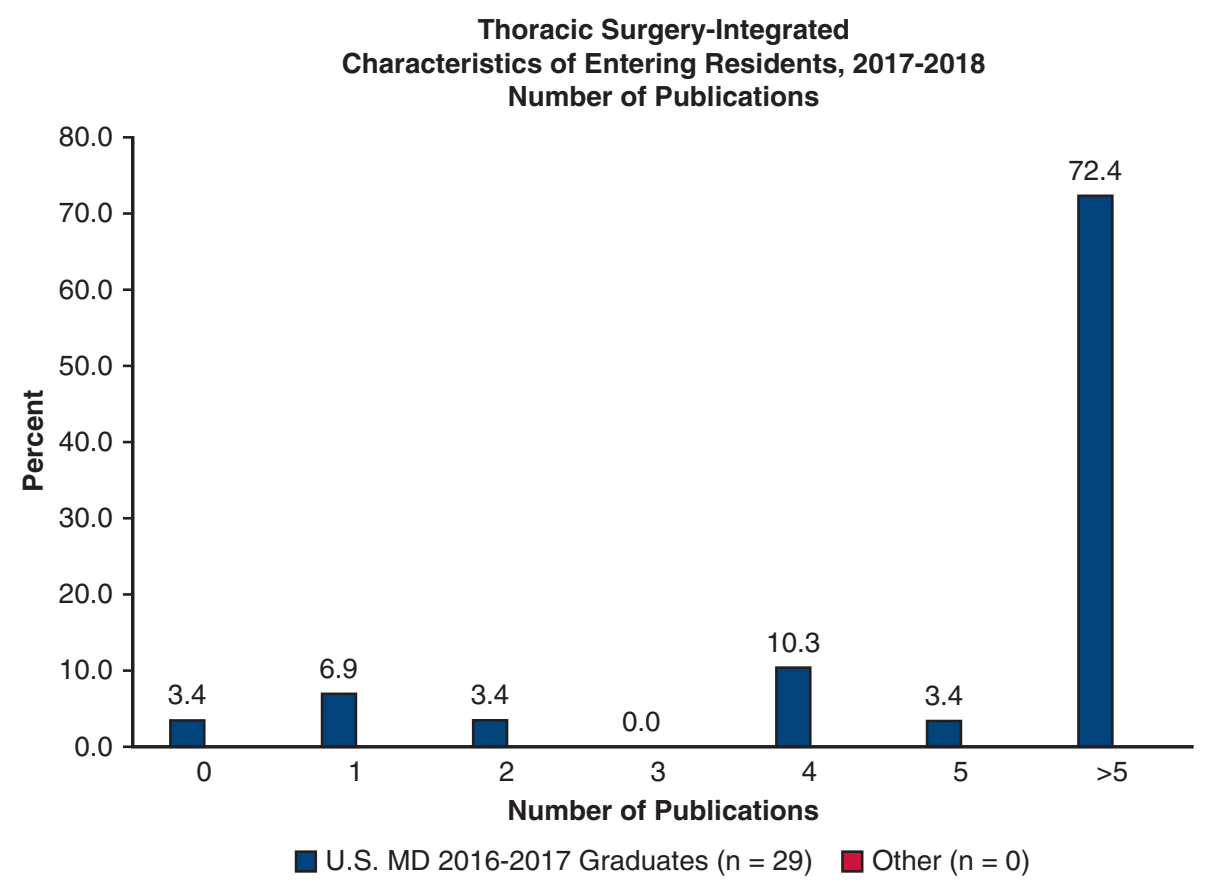

FIGURE 3. Number of publications by graduates entering into integrated thoracic surgery residency programs. Publications are defined as original articles, abstracts, posters, and/or oral presentations. The average trainee entering integrated programs has 10.5 publications. We recommend that applicants have 5 original articles submitted or published by the time they apply, with at least 1 first-author paper. Figure data is lower $(\mathrm{N}=29)$ than residency positions filled in $2017(\mathrm{~N}=34)$ because some data for foreign-trained physicians and others are missing. ${ }^{3,13}$ @2019 Association of American Medical Colleges. May be reproduced and distributed with attribution for educational or noncommercial purposes only. ${ }^{13} A A M C$, Association of American Medical Colleges; US MD, United States Medical Doctor.

important factors for offering interviews and ranking applicants (Table 1). While applicants' mentors will serve as advocates and references when applying to residency, developing a personal relationship with faculty at other institutions, including prospective IPs, can provide an invaluable opportunity. ${ }^{15}$ One should aim to attend at least one major CT surgical society conference per year. Even when not presenting research, a number of funded programs, scholarships, and research grants exist. The American Association for Thoracic Surgeons has a Summer Intern Scholarship as well as a Member for a Day program; the Society of Thoracic Surgeons offers the Looking to the Future Scholarship; the American Heart Association offers student scholarships in both cardiovascular surgery and cardiovascular disease; the Southern Thoracic Surgical Association and regional societies offer other commemorative medical student scholarships. At many of these programs, events are specifically held so that trainees can network with faculty and program directors in a relaxed atmosphere. Search for these opportunities early and reapply if unsuccessful in the first attempt.

Before meetings, scan the program and determine which faculty will be in attendance, giving presentations, or leading lunch lectures. Do not hesitate to briefly introduce oneself to IP residency directors and other surgeons at appropriate times. ${ }^{15}$ Be professional and personable while respecting their time and keeping conversations short. Follow up with a brief e-mail after the meeting, such that if paths cross again in the future, there is a basis for reintroduction. It is surprising how often faculty remember these brief encounters years later when applicants sit for interviews.

\section{CT Surgery Rotations}

Applicants should complete an elective rotation in cardiac and/or thoracic surgery (preferably both) at their home program before leaving for visiting rotations (described below). The home rotation is essential to develop fundamental skills, such that one is not learning the most basic management and procedures while visiting other programs. In the operating room, watch the firstassistant during cases, as trainees will earn the opportunity to assist long before becoming the primary surgeon. Become familiar with each step of establishing cardiopulmonary bypass. Seek out opportunities to put in sternal wires and close the chest, place chest tubes, and bandage incisions. On the wards, become familiar with postoperative intensive care, anticoagulation, and chest tube management. Improve at reading echocardiograms and coronary catheterizations. 
Home rotations provide a foundation for auditioning one's abilities at a program of interest during a visiting elective in CT surgery. There is no surrogate for one's performance on a visiting rotation, which can be a serious consideration when programs rank applicants (Table 1). It is no surprise that programs regard candidates more highly if they have favorably interacted with them for an extended period of time. No matter how impressive an applicant appears on paper or during interviews, the risks of matching an unknown candidate are greater for IPs compared with traditional fellowships, where programs would otherwise have feedback from surgeons who have trained residents for years. ${ }^{5}$ We believe the best way for applicants to distinguish themselves as candidates is to spend time at the institutions in which they are most interested. For those with lesscompetitive applications, doing so before interview invitations may increase their chances of securing an interview at that specific program.

As mentioned, differences in IP curriculum may provide trainees varying degrees of exposure to cardiac, thoracic, congenital surgery, and transplantation. ${ }^{11}$ Applicants with determined career aspirations should take this into consideration when determining programs of greatest interest. Applicants should access the websites of the programs they are particularly interested in well in advance to determine whether there are specific pre-requisites or qualities that program directors are looking for in candidates. For example, programs requiring 2 years of research during residency may place more weight on an applicant's previous research experience and perceived commitment to a career in academic medicine. Other programs prioritize interviewing applicants who have completed away rotations at their program. In any case, the demand for rotations is often high, so it is important to plan on applying for visiting rotations as soon as applications become available.

Away rotations, while important, can be equally harmful if a student is not able to excel in relation to other students and staff. It can be difficult to develop close relationships in just a 1-month rotation, particularly when applicants are unfamiliar with the institutions at which they are visiting. It is extremely important to demonstrate an ability to seamlessly integrate into the clinical service team. Program directors often speak to their coordinators and other personnel who gain exposure to applicants. Do not underestimate the importance of working well with other thoracic surgery trainees, as well as office staff, and other medical students rotating at the same institution during visiting rotations. The importance of exhibiting professional and courteous behavior at all times, unsurprisingly, is essential.

For financial reasons and scheduling logistics, we suggest completing 2 visiting rotations before interview season (which typically begins in mid-November). These rotations should be regarded as 1-month interviews. This invaluable opportunity can offer programs perspective on an applicant's clinical knowledge, technical skills, and ability to work in teams. In the operating room, demonstrate an understanding of anatomy and physiology, surgical indications and contraindications, major operative steps, and potential complications. Overall, visiting students must exhibit a readiness to perform at a resident level.

\section{Obtaining Letters of Recommendation}

Honestly evaluate one's individual performance during a visiting rotation, and only ask for a LOR if one's efforts have truly been exceptional. Faculty recognize the competitive nature of IPs and are usually open to writing LORs. Do not fear that other programs will look down at having spent time at another institution but recognize that these recommendations are also unlikely to significantly influence invitations from other IPs in and of themselves (Table 1). Rather, LORs from visiting rotations should serve as unbiased, outside appraisals of an applicant's clinical performance that provide additional merit to the expectedly favorable recommendations uploaded by home institutions.

Students can submit up to 4 LORs for each IP they apply to. With one visiting rotation as a LOR, we recommend students seek additional letters from the Chair of their home institution's Department of Surgery, as well as their Chief of CT surgery. The final letter should relate to CT surgery and might be a cardiac or thoracic surgeon, or a research mentor. Although only 4 letters can be submitted to any given program, there is no limit to the number of letters one can upload to the Electronic Residency Application Service. As such, for the final letter at each program, it is wise to accrue multiple recommendations and strategically upload them to varying programs. For example, if applicants have 2 close mentors - one who trained at program $X$, and the other at program $\mathrm{Y}$-consider uploading their respective letters to these programs.

\section{PERSONAL STATEMENT}

The personal statement provides a unique opportunity to convey one's individuality among a pool of stellar applicants. Along with perceived commitment to the speciality and LORs, the personal statement is the only factor cited by all responding programs as a consideration in offering interview invitations (Table 1). ${ }^{6}$ Although a remarkable personal statement is unlikely to secure an interview in the absence of the necessary academic and extracurricular merits, a poorly constructed or unclear statement may be sufficient to preclude further consideration of an applicant for interview. A well-constructed personal statement will succinctly articulate the formative experiences that have led applicants to pursue a career in CT surgery. One should illustrate particularly unique skills and attributes that are applicable to specific career aspirations. 
The task is challenging. Begin by asking peers and others who have previously applied to IPs to review drafts as they are rewritten and started anew. Obtain perspectives from a variety of editors, including non-physician $\mathrm{CT}$ administrative personnel who may have extensive experience in reading personal statements that range from exceptionally well-written to poor quality. Asking these valued staff to review personal statements can provide honest and reliable feedback from veterans of the process. When a draft nears completion, consider sending it to surgical mentors for final comments and critiques.

\section{CONCLUSIONS}

In this Young Surgeon's Note, we offer perspective for applicants interested in pursuing IPs while attempting to provide objective benchmarks for developing competitive applications. Exemplary academic performance and extracurricular achievements are undeniable prerequisites. However, perhaps more important is demonstrating an unwavering commitment to CT surgery and ensuring this is articulated throughout one's application and interviews. Although applications will necessarily be customized and illustrate the individuality of each applicant, we hope this Note serves as a guide to early exposure and involvement for applicants interested in pursuing a career in CT surgery via an integrated training pathway.

\section{References}

1. Zhu Y, Goldstone AB, Woo JY. Integrated thoracic surgery residency: current status and future evolution. Semin Thorac Cardiovasc Surg. 2019;31:345-9.

2. Chikwe J, Brewer Z, Goldstone AB, Adams DH. Integrated thoracic residency program applicants: the best and brightest? Ann Thorac Surg. 2011; 92:1586-91.
3. National Resident Matching Program. Results and Data: 2018 Main Residency Match®. Washington, DC: National Resident Matching Program; 2018. Available at: http://www.nrmp.org/wp-content/uploads/2018/04/Main-Match-Resultand-Data-2018.pdf. Accessed September 9, 2019.

4. Association of American Medical Colleges. ERAS Statistics. Washington, DC: Association of American Medical Colleges; 2019. Available at: https://www. aamc.org/services/eras/stats/359278/stats.html. Accessed September 9, 2019

5. Woo YJ, Baker C, Colson Y, Cooke DT, Fann J, Goldstone A. Lessons learned: a roundtable discussion on succeeding in cardiothoracic surgical residency and practice. Semin Thorac Cardiovasc Surg. 2018;30:293-303.

6. National Resident Matching Program. Data Release and Research Committee: Results of the 2018 NRMP Program Director Survey. Washington, DC: National Resident Matching Program; 2018. Available at: https://www.nrmp.org/wpcontent/uploads/2018/07/NRMP-2018-Program-Director-Survey-for-WWW.pdf. Accessed September 9, 2019.

7. Lebastchi AH, Yuh DD. Nationwide survey of US integrated 6-year cardiothoracic surgical residents. J Thorac Cardiovasc Surg. 2014;148: 401-7.

8. Tchantchaleishvili V, LaPar DJ, Stephens EH, Berfield KS, Odell DD, DeNino WF. Current integrated cardiothoracic surgery residents: a Thoracic Surgery Residents Association survey. Ann Thorac Surg. 2015;99: 1040-7.

9. Tchantchaleishvili V, Barrus B, Knight PA, Jones CE, Watson TJ, Hicks GL. Sixyear integrated cardiothoracic surgery residency applicants: characteristics, expectations, and concerns. J Thorac Cardiovasc Surg. 2013;146:753-8.

10. Davis TA, Yang SC. Unmatched integrated cardiothoracic surgery program applicants: where do they end up? Ann Thorac Surg. 2018;106:1556-60.

11. Stephens EH, Walters DM, Eilers AL, Tchantchaleisvili V, Goldstone AB, Gillaspie EA, et al. Variability in integrated cardiothoracic training program curriculum. Ann Thorac Surg. 2017;103:1984-91.

12. Ward ST, Smith D, Andrei AC, Hicks GL Jr, Shermin RJ, Calhoon JH, et al. Comparison of cardiothoracic training curricula: integrated six-year versus traditional programs. Ann Thorac Surg. 2013;95:2051-4.

13. Association of American Medical Colleges. Characteristics of Entering Residents, 2017-2018. Washington, DC: Association of American Medical Colleges; 2019. Available at: https://www.aamc.org/cim/specialty/exploreoptions/list/us/ 341828/thoracic_surgery-integrated.html. Accessed September 9, 2019.

14. Verrier ED. The elite athlete, the master surgeon. J Am Coll Surg. 2017;224: 225-35.

15. Olive J, Luc JGY, Moon MR, Preventza O, Mathisen DJ. How to Maximize Career and Networking Opportunities at Cardiothoracic Surgery Meetings. Presented at: 2019 STS Annual Meeting, May 2019, San Diego, Calif. 